\title{
Familial Cases of Psittacosis: Possible Person-to-person Transmission
}

\author{
Isao ITo*,**, Tadashi IshidA**, Michiaki Mishima*, Makoto OsaWA**, Machiko ArITA**, \\ Toru HaSHIMOTO** and Toshio KISHIMOTO***
}

\begin{abstract}
A 29-year-old woman with primary myelofibrosis developed severe pneumonia, and 20 days later her 31-year-old sister also contracted pneumonia. The first patient had been in contact with parakeets but the second patient had not been in contact with any birds. Psittacosis was diagnosed in both cases by microplate immunofluorescence antibody technique. Person-to-person transmission between the sisters was suspected to have taken place.

(Intrenal Medicine 41: 580-583, 2002)
\end{abstract}

Key words: ornithosis, Chlamydia psittaci, microplate immunofluorescence antibody technique, primary myelofibrosis, splenomegaly, computed tomography

\section{Introduction}

Psittacosis is an infection caused by Chlamydia psittaci and it is contracted by the inhaling of discharges from infected parakeets. Although person-to-person transmission of C. psittaci infection is believed to be rare, several cases including nosocomial infection have been reported (1-6). Furthermore, $C$. psittaci is not considered an opportunistic pathogen. Here we present an interesting case of psittacosis transmission. First, a primary myelofibrosis patient was infected probably from parakeets with which she had direct contact and developed severe psittacosis. Secondly, her healthy sister who had no contact with birds became infected. Person-to-person transmission between the two sisters was thought to have taken place.

\section{Case Report}

\section{Case 1}

A 29-year-old woman was admitted to Kurashiki Central
Hospital because of a one-week history of anorexia and fever. She had lived with her parents and elder sister (Case 2). She had been diagnosed with primary myelofibrosis and had been under observation without therapy for five months. Gallium scan which had been taken for the evaluation of primary myelofibrosis revealed hepatosplenomegaly and is shown in Fig. 1. Before the onset of fever, she sometimes visited a confectionery where three apparently healthy parakeets were kept as pets. The patient developed a dry cough, dyspnea and diarrhea, and became severely ill with fever of $40.4^{\circ} \mathrm{C}$, tachycardia of 120 beats/min with irregular rhythm and tachypnea of $24 / \mathrm{min}$. On auscultation, inspiratory fine crackles were heard on the left upper and right middle lung field anteriorly, and all over the right lung posteriorly. Systolic murmur was also heard. On abdominal examination, the spleen was palpable five finger breadths beneath the left costal margin. Arterial blood gas analysis on room air revealed that the oxygen partial pressure was $48 \mathrm{mmHg}$ and carbon dioxide partial pressure $32 \mathrm{mmHg}$. Complete blood count was as follows; red cell count $244 \times 10^{4} / \mu \mathrm{l}$, hemoglobin $7.1 \mathrm{~g} / \mathrm{dl}$, hematocrit $23.3 \%$, white blood cell count $4,300 / \mu \mathrm{l}$ with myeloblast $3.5 \%$, and platelet count $17.0 \times 10^{4} /$ $\mu 1$. The erythrocyte sedimentation rate increased to more than $154 \mathrm{~mm}$ per an hour. Serum chemistry revealed that asparate aminotransaminase was $54 \mathrm{IU} / \mathrm{ml}$, alanine aminotransaminase $134 \mathrm{IU} / \mathrm{ml}$, lactic dehydrogenase $1,526 \mathrm{IU} / \mathrm{ml}$, alkaline phosphatase $789 \mathrm{IU} / \mathrm{ml}$, and gamma guanosine triphosphate 199 IU $/ \mathrm{ml}$. C-reactive protein was highly elevated to $35.1 \mathrm{mg} / \mathrm{dl}$. She did not expectrate any sputum for microbiological examinations, and blood culture was sterile. Chest X-ray revealed bilateral infiltration of alveolar shadow and ground-glass shadow with air bronchogram (Fig. 2). Chest computed tomography showed areas of air-space consolidation mixed with areas of ground-glass attenuation affecting all lobes bilaterally (Fig. 3). Pleural effusion was absent. Two hundred milligrams minocycline per day and $2 \mathrm{~g}$ flomoxef were given intravenously. On day 5 , minocycline was stopped because asparate aminotransaminase had increased to $324 \mathrm{IU} / l$. Her high-grade fever was sustained and daily 400 milligrams clarithromycin

From *the Department of Respiratory Medicine, Graduate School of Medicine, Kyoto University, Kyoto, **the Department of Respiratory Medicine, Kurashiki Central Hospital, Kurashiki and ***the Department of Virology I, Laboratory of Rickettsia \& Chlamydia, National Institute of Infectious Diseases Received for publication October 22, 2001; Accepted for publication February 27, 2002

Reprint requests should be addressed to Dr. Isao Ito, the Department of Respiratory Medicine, Graduate School of Medicine, Kyoto University, 54 Shogoinkawaharacho, Sakyo-ku, Kyoto 606-8507 


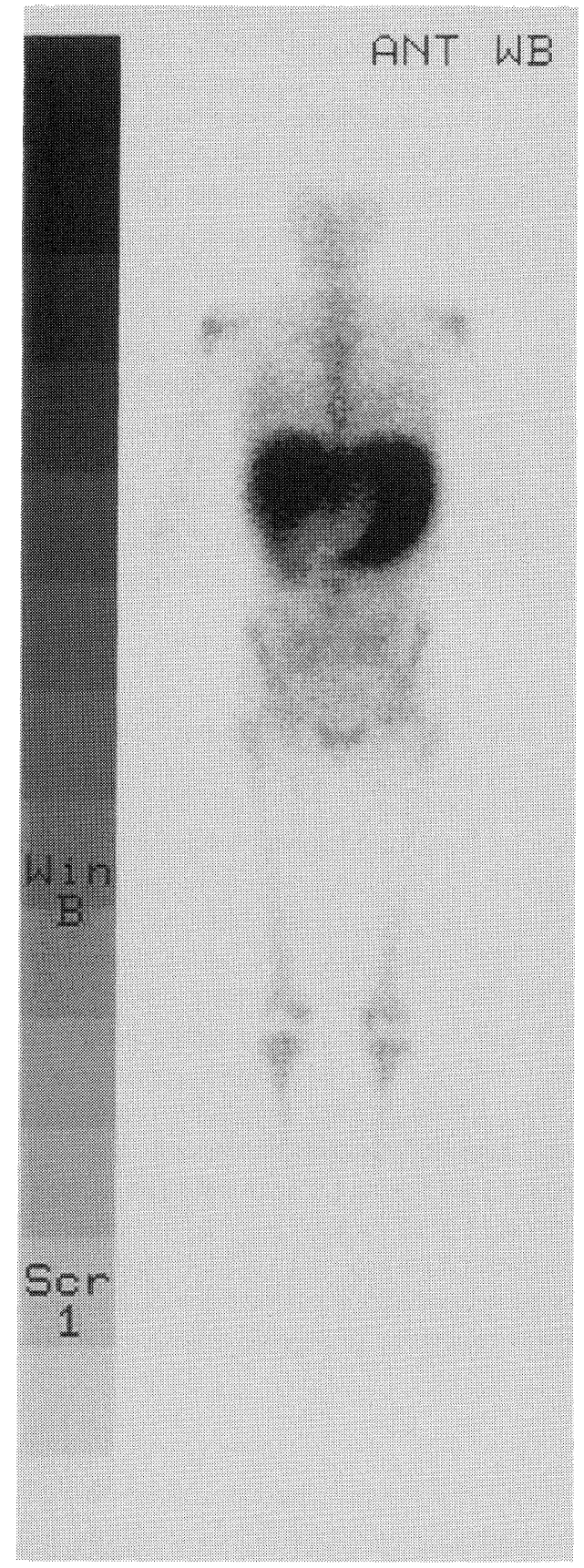

Figure 1. Gallium scan of case 1. Enormous hepatosplenomegaly is noted because of the underlying disease, primary myelofibrosis.

per oral was started on day 12 . Her condition improved and Creactive protein turned to negative on day 39 . The three parakeets stayed healthy and none was lost.

\section{Case 2}

A 31-year-old female visited the outpatient clinic of Kurashiki Central Hospital 20 days after patient 1 had been

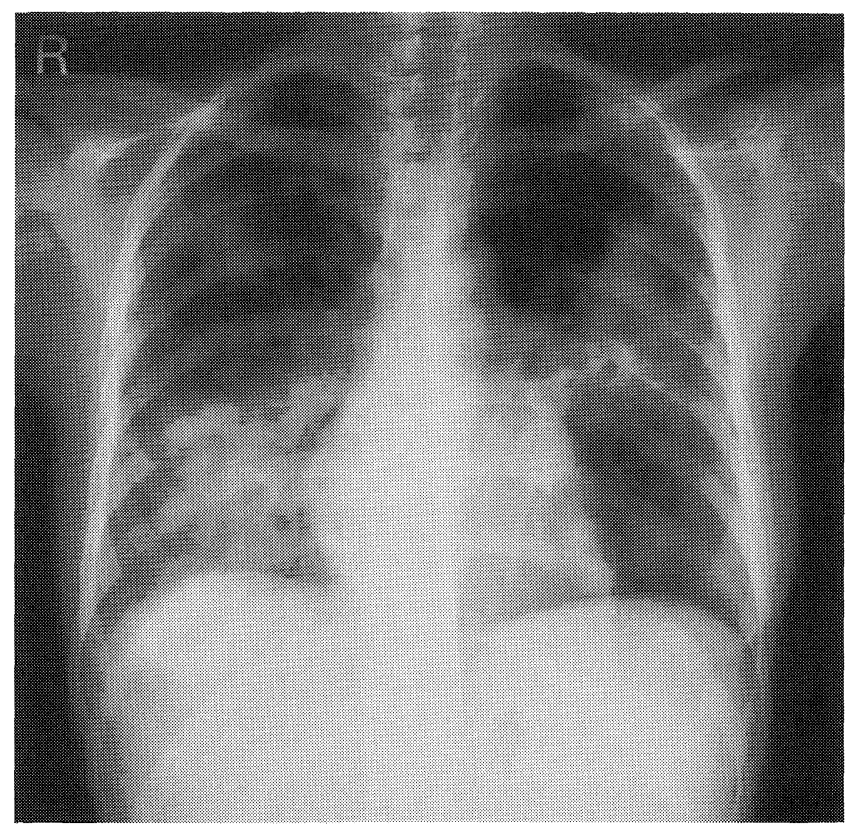

Figure 2. Chest $\mathrm{X}$-ray of case 1 revealed bilateral infiltration with air bronchogram. Shadows located in the peri-bronchial areas are noted.

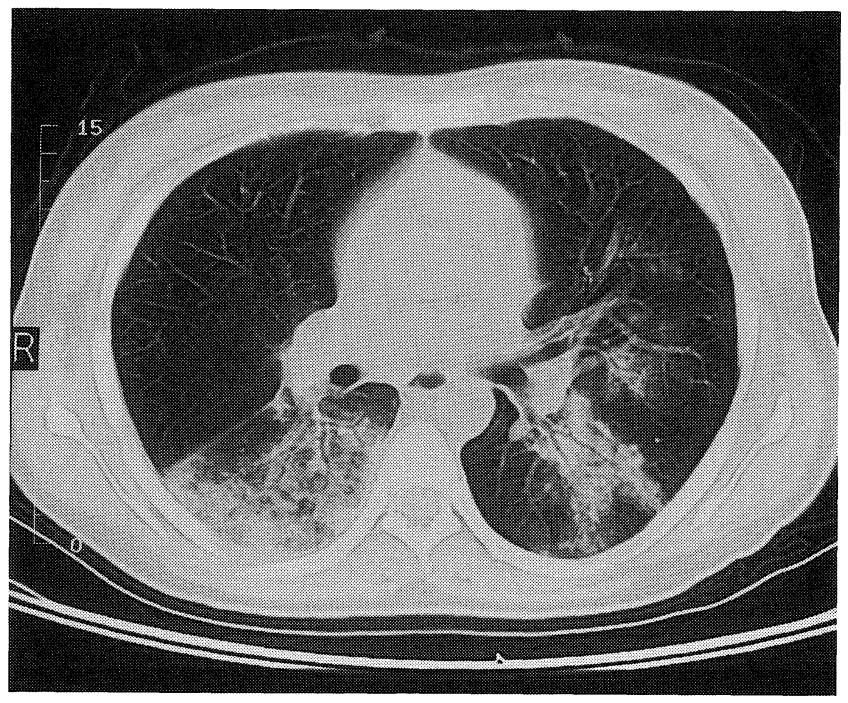

Figure 3. Chest computed tomography of case 1 showed multilobar bilateral shadows. Areas of air-space consolidation mixed with ground-glass attenuation are noted as the main appearance. Small nodular shadows of obscure margin are also noted.

admitted, with a sudden onset of high fever and dry cough. She was the elder sister of patient 1 and had lived with her. Patient 2 had been in good health and had no recent contact with birds and domestic animals. Her body temperature was $38.7^{\circ} \mathrm{C}$, and 
physical examination on the chest and the abdomen did not show any abnormalities. The leukocyte count was $7,200 / \mu 1$ with a normal differential cell count. C-reactive protein was $8.9 \mathrm{mg} /$ dl. Chest X-ray revealed pneumonia of the left lung with a ground-glass appearance (Fig. 4). Sputum culture was not performed because she did not produce any sputum. She was given 400 milligrams clarithromycin per day orally as an outpatient. After 7 days, pneumonia improved on chest X-ray. The parents of the sisters did not develop any infectious symptoms.

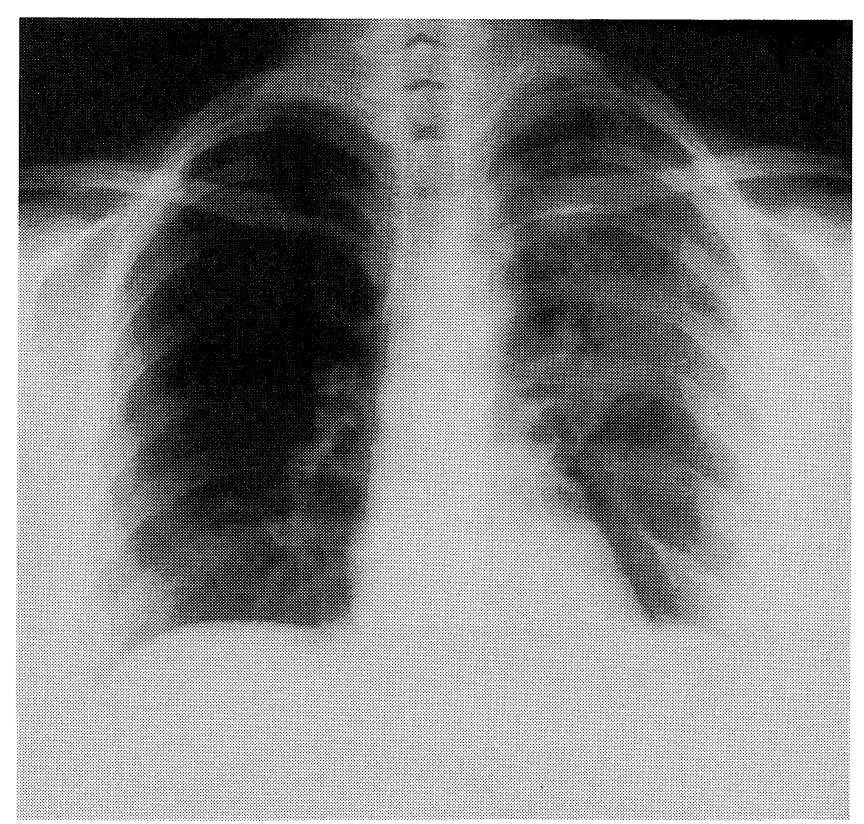

Figure 4. Chest radiograph of case 2 showed ground-glass shadow in the upper to the lower field of the left lung. Air bronchogram is visible

\section{Serological study}

Sera from the two cases were tested by Chlamydia complement-fixing (CF) antibodies for commercial ornithosis antigen and by microplate immunofluorescence antibody (MFA) technique (7). The results are shown in the Table 1. CF test in case 1 showed marked elevation of the titer, and CF antibody titer in case 2 was highly elevated but showed no significant change. In case 1, MFA titers of three Chlamydia species were significantly elevated between acute and convalescent periods. The antibody titers to Chlamydia psittaci were the highest of the three. In case 2, the antibody titers to Chlamydia pneumoniae had already been elevated and showed no rise, which indicates patient 2 had already been infected with $C$. pneumoniae. Antibody titers to $C$. psittaci solely showed a four-fold rise between acute and convalescent periods in case 2 . The two cases were respectively diagnosed as $C$. psittaci infection.

\section{Discussion}

Our cases of psittacosis are interesting for two reasons. First, person-to-person transmission probably occurred between the two patients. Second, patient 1 had primary myelofibrosis as an underlying disease. We suppose the parakeets, with which the patient 1 had direct contact, were the primary source of infection and the infection was then transmitted from patient 1 to patient 2. While person-to-person transmission of $C$. pneumoniae is thought to be common, that of $C$. psittaci is very rare. Our two cases were each diagnosed with $C$. psittaci infection by MFA. Serological cross-reactivity between $C$. psittaci and $C$. pneumoniae in CF tests for ornithosis may account for some reported mass outbreaks considered to be ornithosis without avian contact (8). In addition, in most of the mass outbreaks of "true" ornithosis, common sources of infection between infected patients were identified, and all the members were suspected to be infected from these sources. We could find only a few reports of ornithosis outbreaks in which sec-

Table 1. Serological Studies

Antibody titers

\begin{tabular}{|c|c|c|c|c|c|c|c|c|c|c|c|}
\hline \multirow{3}{*}{ Patient } & \multirow{3}{*}{$\begin{array}{l}\text { Days from } \\
\text { Patient l's admission }\end{array}$} & \multirow{3}{*}{$\begin{array}{c}\text { Chlamydia } \\
\text { CF test }\end{array}$} & \multicolumn{9}{|c|}{ MFA test } \\
\hline & & & \multicolumn{3}{|c|}{ C. psittaci } & \multicolumn{3}{|c|}{ C. pneumoniae } & \multicolumn{3}{|c|}{ C. trachomatis } \\
\hline & & & $\operatorname{IgM}$ & $\operatorname{IgA}$ & IgG & $\operatorname{IgM}$ & $\operatorname{IgA}$ & $\mathrm{IgG}$ & IgM & $\operatorname{IgA}$ & $\operatorname{IgG}$ \\
\hline \multirow[t]{5}{*}{1} & 1 & 8 & $<8$ & $<16$ & $<32$ & $<8$ & $<16$ & 256 & $<8$ & $<16$ & $<32$ \\
\hline & 15 & 128 & & & & & & & & & \\
\hline & 25 & & 8 & 256 & 2,048 & $<8$ & 128 & 1,024 & $<8$ & 128 & 1,024 \\
\hline & 29 & 1,024 & & & & & & & & & \\
\hline & 34 & & $<8$ & 512 & 4,096 & $<8$ & 128 & 2,048 & $<8$ & 256 & 1,024 \\
\hline \multirow[t]{2}{*}{2} & 26 & 32 & $<8$ & $<16$ & 128 & $<8$ & 32 & 512 & $<8$ & $<16$ & $<32$ \\
\hline & 40 & 32 & $<8$ & $<16$ & 512 & $<8$ & 32 & 512 & $<8$ & $<16$ & $<32$ \\
\hline
\end{tabular}

MFA: microplate immunofluorescence antibody, CF: complement fixation. 


\section{Person-to-person Transmission of Psittacosis}

ondarily infected patients had never had direct contact with birds and person-to-person transmissions were presumed to have occurred (1-6). Between our two patients, this mode of transmission is probable for three reasons; they lived together, the onset of the case 2 was 25 days after that of the case 1 , and only patient 1 had contact with birds. This mode of infection is often difficult to determine with certainty, and is more likely with virulent forms of the disease (3). In the present cases, the disease transmitted to only one of the other three family members, i.e. the elder sister (patient 2), and the patients' parents did not present any respiratory symptoms. In the literature, an avian source of infection was not identified in as many as onefourth of cases (9). However, it appears nearly impossible for patient 1 and patient 2 to have coincidentally become infected with $C$. psittaci from respective sources at almost the same period. After inhaling $C$. psittaci, the organism disseminates and reaches the reticuloendothelial cells of the liver and spleen, and replicates in the local mononuclear phagocytes (10). In myelofibrosis patients, the liver and the spleen are enlarged for increased extramarrow hemopoiesis, but Kupffer cell function is thought to be normal. To our knowledge, ornithosis in a primary myelofibrosis patient has not previously been reported. Patient 1 with primary myelofibrosis as an underlying disease had an enlarged spleen and developed severe pneumonia. It is speculated that the severity of disease in case 1 was due to the large and favorable environment for the pathogen which proliferates in phagocytes.

\section{References}

1) Olson BJ, Treuting WL. An epidemic of a severe pneumonitis in the Bayou region of Louisiana. Public Health Rep (Wash) 59: 1299-1311, 1944.

2) Jernelius H, Pettersson B, Schvarcz J, Vahlne A. An outbreak of ornithosis. Scand J Infect Dis 7: 91-95, 1975.

3) Broholm KA, Bottiger M, Jernelius H, Johansson M, Grandien M, Solver K. Ornithosis as a nosocomial infection. Scand J Infect Dis 9: 263-267, 1977.

4) Byrom NP, Walls J, Mair HJ. Fulminant psittacosis. Lancet 1 (8112): 353-356, 1979.

5) Bourke SJ, Carrington D, Frew CE, Stevenson RD, Banham SW. Serological cross-reactivity among chlamydial strains in a family outbreak of psittacosis. J Infect 19: 41-45, 1989

6) Hughes C, Maharg P, Rosario P, et al. Possible nosocomial transmission of psittacosis. Infect Control Hosp Epidemiol 18: 165-168, 1997.

7) Amano M, Suzuki M, Tanaka H, Oota S, Bessho H, Matsumoto A. Clinical studies on urogenital infection with Chlamydia trachomatis. 1. Detection of antibodies to chlamydiae in patient sera by means of the microplate immunofluorescence antibody technique (MFA). Nippon Hinyokika Gakkai Zasshi 76: 1294-1302, 1985 (in Japanese).

8) Pether JVS, Wang SP, Grayston JT. Chlamydia pneumoniae, strain TWAR, as the cause of an outbreak in a boys' school previously called psittacosis. Epidemiol Infect 103: 395-400, 1989.

9) Scholossberg D. Chlamydia psittaci. Infectious Diseases. in: Mandell GL, Bennett JE, Dolin R, Eds. 4th ed. Churchill Livingstone, New York, 1995: 1693-1695.

10) Tuazon CU, Murray HW. Atypical pneumonias. Respiratory Infections: Diagnosis and Management. in: Pennington JE, Ed. 3rd ed. Raven Press, New York, 1994: 407-434. 